\title{
Carotid Intraplaque-Hemorrhage Volume and Its Association with Cerebrovascular Events
}

\author{
(D) L. Saba, (D) G. Micheletti, (D)W. Brinjikji, (D) P. Garofalo, (D). Montisci, (D)A. Balestrieri, (D).S. Suri, (D).K. DeMarco, (D) G. Lanzino, \\ and (D) R. Sanfilippo
}

\begin{abstract}
BACKGROUND AND PURPOSE: Our aim was to assess the relationship between volume and percentage of intraplaque hemorrhage measured using CT and the occurrence of cerebrovascular events at the time of CT.

MATERIALS AND METHODS: One-hundred-twenty-three consecutive subjects (246 carotid arteries) with a mean age of 69 years who underwent CTA were included in this retrospective study. Plaque volume of components and subcomponents (including intraplaque hemorrhage volume) was quantified with dedicated software.

RESULTS: Forty-six arteries were excluded because no plaque was identified. In the remaining 200 carotid arteries, a statistically significant difference was found between presentation with cerebrovascular events and lipid volume $(P=.002)$, intraplaque hemorrhage volume $(P=.002)$, percentage of lipid $(P=.002)$, percentage of calcium $(P=.001)$, percentage of intraplaque hemorrhage $(P=.001)$, percentage of lipid-intraplaque hemorrhage $(P=.001)$, and intraplaque hemorrhage/lipid ratio $(P=.001)$. The highest receiver operating characteristic area under the curve was obtained with the intraplaque hemorrhage volume with a value of $0.793(P=.001)$, percentage of intraplaque hemorrhage with an area under the curve of $0.812(P=.001)$, and the intraplaque hemorrhage/lipid ratio with an area under the curve value of $0.811(P=.001)$.
\end{abstract}

CONCLUSIONS: Results of our study suggest that Hounsfield unit values $<25$ have a statistically significant association with the presence of cerebrovascular events and that the ratio intraplaque hemorrhage/lipid volume represents a strong parameter for the association of cerebrovascular events.

ABBREVIATIONS: AUC = area under the curve; IPH = intraplaque hemorrhage; ROC = receiver operating characteristic

S everal studies have demonstrated, in recent years, that the degree of stenosis should not be considered the only parameter to identify carotid plaque at risk of distal embolization and that additional plaque features can increase or reduce risk of plaque rupture and embolic events. ${ }^{1-4}$ In particular, intraplaque

Received April 7, 2019; accepted after revision July 15.

From the Departments of Radiology (L.S., G.M., P.G., A.B.) and Vascular Surgery (R.M., R.S.), Azienda Ospedaliero Universitaria, Monserrato (Cagliari), Italy; Departments of Radiology (W.B.) and Neurosurgery (G.L.), Mayo Clinic, Rochester, Minnesota; Stroke Monitoring and Diagnostic Division (J.S.S.), AtheroPoint, Roseville, California; Point-of-Care Devices (I.S.S.), Global Biomedical Technologies, Roseville, California; Department of Electrical Engineering (J.S.S.), University of Idaho, Moscow, Idaho (Affiliated); and Department of Radiology (I.K.D.), Walter Reed Medical Center, Bethesda, Maryland.

The views expressed in this article are those of the author and do not reflect the official policy of the Department of Army/Navy/Air Force, Department of Defense, or US Government.

The identification of specific products or scientific instrumentation does not constitute endorsement or implied endorsement on the part of the author, Department of Defense, or any component agency.

Please address correspondence to Luca Saba, MD, Department of Radiology, Azienda Ospedaliero Universitaria, di Cagliari—Polo di Monserrato s.s. 554 Monserrato (Cagliari) 09045, Italy; e-mail: lucasaba@tiscali.it

http://dx.doi.org/10.3174/ajnr.A6189 hemorrhage (IPH) has been convincingly associated with a higher risk of ipsilateral cerebrovascular events. ${ }^{5,6}$

Although MR imaging has been widely used to identify $\mathrm{IPH},{ }^{7-9}$ recent evidence suggests that $\mathrm{CT},{ }^{10}$ using a threshold of attenuation values of $<25 \mathrm{HU}$ in the carotid artery, can consistently identify the presence of IPH. Moreover, with improved algorithmic and hardware evolution, there has been an increasing role of volumetric quantification of tissue components for plaque characterization. ${ }^{11-14}$

In the present study, we assessed the relationship between volume and the percentage of IPH measured using software analysis in volumetric CT and the occurrence of cerebrovascular events (stroke and TIA).

\section{MATERIALS AND METHODS Study Design and Patient Population}

Institutional review board approval for this study was obtained, and patient consent was waived because of the retrospective nature. On the basis of a power calculation (type I error, $\alpha=.05$; 
type II error, $\beta=0.1$; area under the curve [AUC] null hypothesis value $=0.5$; AUC significant value $=0.7$, pooled group), we estimated that a sample size of at least 130 (with a $30 \%$ IPH prevalence) carotid arteries would be sufficient to investigate the potential effect of CT-detected IPH versus the occurrence of cerebrovascular events. We decided to also include a correction factor of $10 \%$, yielding a necessary sample size of 143 carotid arteries. Moreover, because in each subject, there are 2 carotid arteries and this determined a bias in the model, we decided to study 200 carotid arteries to avoid the inference determined by the 2 carotid arteries in each patient.

Consecutive subjects who underwent CT of the carotid arteries in our hospital from March 2013 were included until the threshold of 200 carotid arteries was reached (January 2014) for a total of 246 carotid arteries in 123 subjects ( 94 men, 29 women; mean age, 69 years; age range, $45-86$ years). For each subject, when both carotid arteries showed atherosclerotic plaque, the left and right sides were included. Plaque was defined according to the Mannheim consensus ${ }^{15}$ as a carotid wall thickness of $>1500 \mu \mathrm{m}$.

In cases in which only 1 carotid artery was pathologic, the normal side (46 carotid arteries) was excluded from analysis, leaving 200 arteries with an atherosclerotic plaque for analysis.

Quantification of the degree of stenosis and plaque analysis was performed using CTA according to previously published criteria. ${ }^{16,17}$ Carotid sonography is used as a screening tool to identify carotid stenosis, and CTA was performed under the following circumstances: 1) Carotid sonography showed a pathologic stenosis ( $>50 \%$ measured with the NASCET criteria ${ }^{18}$ ) or features related to plaque vulnerability (ulcerations, irregular surface); 2) sonography could not adequately assess the degree of stenosis and plaque characteristics because of anatomic conditions; 3) diabetes screening; and 4) presurgery analysis. Moreover, all subjects with cerebrovascular events underwent CTA of the carotid arteries. The neurologic status at the time of CT was classified as symptomatic or asymptomatic according to the neurologic assessment documented in the clinical chart review using the Trial of Org 10172 in Acute Stroke Treatment (TOAST) criteria. ${ }^{19,20}$ The maximum timing between events and imaging to consider a subject as symptomatic was 1 week. In the case of $>1$ week between ischemic symptoms and CTA of carotid arteries, the patient was excluded. We defined as symptomatic those patients with TIA or stroke, considering TIA as a brief $(<24$ hour) episode of neurologic dysfunction such as dysarthria, dysphasia, hemiparesis, or hemiparesthesia and monocular blindness. If the episodes of neurologic dysfunction lasted $>24$ hours, the patient was considered to have a stroke. In case of doubt with other pathologies (eg, hypoglycemia, migraine, postparoxysmal neurologic dysfunction), we excluded patients from the analysis. Asymptomatic patients had no history of either remote or recent symptoms at the time of the examination. Clinical classification into symptomatic and asymptomatic was based on the assessment of the clinician evaluating the patient and ordering the diagnostic study and was extracted from the chart. We considered symptomatic patients those who had plaque in the carotid artery ipsilateral to the cerebrovascular event.
Moreover, we excluded patients with the following conditions: 1) concomitant intracranial pathology such as brain tumor, abscess, and encephalitis; and 2) the presence of a cardioembolic source documented by a cardiologist.

\section{CTA Technique}

Patients were studied using a 16-detector row CT system (Brilliance; Philips Healthcare, Best, the Netherlands). CT images were obtained with coverage from the aortic arch to the carotid siphon in a caudocranial direction, and examinations were performed before and after the administration of contrast material. An angiographic phase was obtained with the administration of $80 \mathrm{~mL}$ of prewarmed contrast medium, Ultravist 370 (iopromide; Bayer HealthCare, Berlin, Germany) into a cubital vein using a power injector at a flow rate of $4-5 \mathrm{~mL} / \mathrm{s}$ and a 16-ga intravenous catheter followed by $30 \mathrm{~mL}$ of saline flush. CT technical parameters included the following: section thickness $=0.6 \mathrm{~mm}$, section interval $=0.3 \mathrm{~mm}$, matrix size $=512 \times 512$ pixels, $\mathrm{FOV}=14-$ $19 \mathrm{~cm}$. A C-filter algorithm of reconstruction was applied.

\section{IPH and Plaque Volume Component Analysis Quantification}

Two radiologists (L.S. and A.B. with 11 and 8 years of experience in CTA, respectively) blinded to clinical information regarding symptomatic status performed all measurements of Hounsfield units using as window/level settings, $\mathrm{W}=850: \mathrm{L}=300 .^{21}$ Volume analysis was performed with dedicated software (Elucid Bioimaging, Wenham, Massachusetts) to semi-automatically quantify the subcomponent volume. ${ }^{22,23}$ With this software, it is possible to identify attenuation values of all the voxels within a volume, and by means of applying some thresholds, it is possible to classify the tissues according to the attenuation values (Fig 1). For this analysis, we considered 5 classes: 3 , as suggested by de Weert et $\mathrm{al}^{24}$ in which voxels identifying lipid tissues were $<60 \mathrm{HU}$, fibrous tissue between 60 and 130 $\mathrm{HU}$, and calcium tissue $>130 \mathrm{HU} \cdot{ }^{10,24}$ Two additional classes (4 and 5) were added by splitting the lipid: the fourth class was the IPH for values $<25 \mathrm{HU}$ according to the findings by Saba et al, ${ }^{10}$ whereas the fifth class was the lipid-IPH, which included all the voxels with Hounsfield unit values between 26 and $59 \mathrm{HU}$.

We also calculated the percentages of these components, and finally, a ratio was introduced as the ratio of IPH/lipid volume (with values between 0 , if no IPH was present, and 1, if all the lipid plaque component was due to IPH).

\section{IPH Volume Dichotomization}

After the volume calculation of the IPH, 5 thresholds were selected to obtain a dichotomization and subsequently test the effect of the presence/absence of IPH versus symptoms using a 6hypothesis scenario. We considered the following 6 thresholds of IPH volume: 10, 50, 100, 150, 200, and $250 \mathrm{~mm}^{3}$.

\section{Statistical Analysis}

In this study, continuous data were described as the mean \pm SD. Receiver operating characteristic (ROC) curve analysis was performed between volume and volume subcomponents (lipid, mixed, calcified, IPH, lipid-IPH tissue), percentage of variable of 


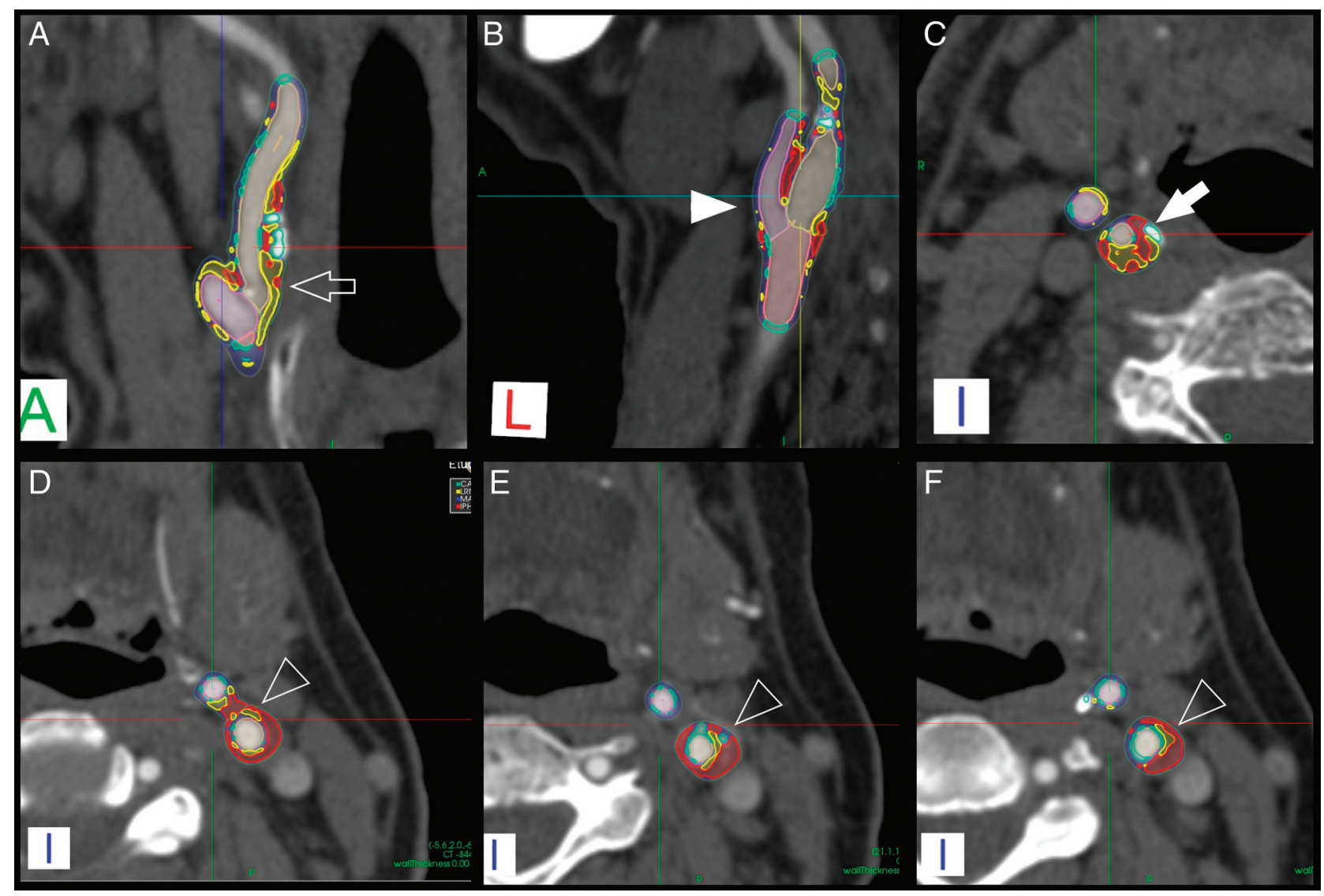

FIG 1. The first case is a 69-year-old male patient with right stroke who underwent CTA that showed a large IPH component of $107 \mathrm{~mm}^{3}(A-C)$. $A$, The coronal view of the carotid CTA is given with the segmentation of the software (white open arrow). $B, A$ coronal cut of the postprocessed carotid arteries is shown (white arrowhead). C, The white arrow indicates the internal carotid artery in the axial selected section. The legend of the chromatic scale is the following: red = IPH; yellow = lipid-IPH component; blue = mixed component; green = calcified component. The second case is a 73-year-old male patient with left MCA stroke with an IPH/lipid ratio of $0.93(D-F)$. $D-F$, Three axial slices from the bifurcation upward were selected showing the presence of a large IPH and the small amount of lipid-IPH (white arrowheads).

the subcomponents, ratio of IPH/lipid, and the presence of cerebrovascular events. The normality of each continuous group was tested using the Kolmogorov-Smirnov $Z$-test, and different values in groups with and without cerebrovascular symptoms were compared using the Mann-Whitney test. The dichotomized IPH values according to the thresholds were tested versus the presence/ absence of cerebrovascular events using a $\chi^{2}$ test. A $P$ value $<.05$ indicated a statistically significance association, and all values were calculated using a 2-tailed significance level. Statistical analysis was performed with the SPSS 13.0 Statistical Package (IBM, Armonk, New York). Graphics were plotted with MedCalc 15.0 software (MedCalc Software, Mariakerke, Belgium).

\section{RESULTS}

\section{General Results}

No patients were excluded due to suboptimal image quality. Of the 123 patients, 46 were symptomatic ( 15 strokes, 31 transient ischemic attacks) and 77 were asymptomatic. General plaque characteristics and their subcomponent volume and percentages are summarized in Table 1. No statistically significant difference was found for the common cerebrovascular risk factors between symptomatic and asymptomatic patients. However, there were statistically significant differences in the lipid volume $(P=.002)$,
IPH volume $(P=.001)$, percentage of lipid $(P=.002)$, percentage calcium $(P=.001)$, percentage of IPH $(P=.0001)$, percentage of lipid-IPH $(P=.0001)$, and the IPH/lipid ratio $(P=.001)$. Boxplots are given in Fig 2.

\section{ROC Curve Analysis}

The ROC curve analysis for the total plaque component and subcomponent volume versus the presence of cerebrovascular symptoms is given in Fig $3 A$. Table 2 summarizes general ROC results from the volume analysis. The best ROC AUC was obtained with the IPH volume, with a value of $0.793(P=.001)$.

The ROC curve analysis was also performed for the percentage of plaque components versus the presence of cerebrovascular symptoms, and the ROC plot is shown in Fig 3B. Table 2 also summarizes the general ROC results from volume analysis. The best performance was obtained by the percentage of IPH with an AUC of $0.812 ; P=.001)$. Also, the IPH/lipid ratio showed a very good AUC, with a value of $0.811(P=.001)$.

\section{IPH Volume Dichotomization}

In Table 3, the $\chi^{2}$ results for the different threshold volumes of IPH and cerebrovascular symptoms are summarized. The best 


\begin{tabular}{|c|c|c|c|c|}
\hline Cerebrovascular Symptoms & Yes & No & $P$ Value & Test \\
\hline \multicolumn{5}{|l|}{ Demographics } \\
\hline Age (mean) (95\% Cl) (yr) & $70(66-74)$ & $68(65-71)$ & .37 & Paired Student $t$ \\
\hline Sex $($ male $=93)$ & $80 \%(37 / 46)$ & $74 \%(57 / 77)$ & .55 & $\chi^{2}$ \\
\hline Hypertension & $26 \%(12 / 46)$ & $27 \%(42 / 154)$ & .98 & $x^{2}$ \\
\hline CAD & $50 \%(23 / 46)$ & $45 \%(70 / 154)$ & .71 & $x^{2}$ \\
\hline Smoking status & $43 \%(20 / 46)$ & $30 \%(46 / 154)$ & .12 & $x^{2}$ \\
\hline Diabetes & $7 \%(3 / 43)$ & $7 \%(11 / 154)$ & .85 & $x^{2}$ \\
\hline Dyslipidemia & $28 \%(13 / 46)$ & $32 \%(49 / 154)$ & .79 & $x^{2}$ \\
\hline \multicolumn{5}{|l|}{ Plaque composition } \\
\hline Total plaque volume $\left(\mathrm{mm}^{3}\right)$ & 793 (565-984) & $560(503-669)$ & .105 & Mann-Whitney \\
\hline Lipid volume $\left(\mathrm{mm}^{3}\right)$ & $187(132-240)$ & 79 (63-101) & $.002^{\mathrm{a}}$ & Mann-Whitney \\
\hline Mixed volume $\left(\mathrm{mm}^{3}\right)$ & $471(400-544)$ & $318(290-367)$ & .062 & Mann-Whitney \\
\hline Calcified volume $\left(\mathrm{mm}^{3}\right)$ & $103(70-150)$ & $128(109-156)$ & .16 & Mann-Whitney \\
\hline $\mathrm{IPH}$ volume $\left(\mathrm{mm}^{3}\right)$ & $115(74-160)$ & $2(0-9)$ & $.001^{\mathrm{a}}$ & Mann-Whitney \\
\hline Lipid-IPH volume $\left(\mathrm{mm}^{3}\right)$ & $61(37-110)$ & 67 (60-87) & .14 & Mann-Whitney \\
\hline$\%$ of lipid & $23(21-30)$ & $17(14-18)$ & $.002^{\mathrm{a}}$ & Mann-Whitney \\
\hline$\%$ of mixed & $58(56-63)$ & $59(56-61)$ & .51 & Mann-Whitney \\
\hline$\%$ of calcium & $13(12-17)$ & $21(18-22)$ & $.001^{\mathrm{a}}$ & Mann-Whitney \\
\hline$\%$ of IPH & $15(12-18)$ & $1(0-3)$ & $.001^{\mathrm{a}}$ & Mann-Whitney \\
\hline$\%$ of lipid-IPH & $8(6-11)$ & $13(12-14)$ & $.001^{\mathrm{a}}$ & Mann-Whitney \\
\hline IPH/lipid ratio & $0.69(0.59-0.73)$ & $0.019(0-0.064)$ & $.001^{\mathrm{a}}$ & Mann-Whitney \\
\hline
\end{tabular}

Note:-CAD indicates coronary artery disease.

a Significant.

association was found by considering a threshold of $50 \mathrm{~mm}^{3}(P=$ $.001, \chi^{2}=43.913$, contingency coefficient $=0.424$ ).

\section{DISCUSSION}

Several studies have recently shown that carotid artery plaque characteristics are associated with a risk of rupture and subsequent distal embolization. ${ }^{2,3,5,24}$ In this study, we assessed the relationship between volume and percentage of IPH and other plaque components in the carotid artery detected with $\mathrm{CT}$ and their association with symptomatic status. We observed a significant association between the presence of ipsilateral cerebrovascular events and the absolute volume of IPH as well as plaque lipid content. Moreover, the ratio of IPH/lipid volume was strongly associated with cerebrovascular events.

Among factors involved with plaque rupture, IPH is one of the most dangerous, and its noninvasive identification is an important step for correct risk stratification..$^{5-8}$ MR imaging is considered the best technique for the detection of IPH, while the value of CT is debated. However, a recent study ${ }^{10}$ suggests that a threshold of $\leq 25 \mathrm{HU}$ is strongly associated with the presence of IPH on CT.

One of the main limitations of carotid plaque analysis was the fact that various imaging techniques do not account for the heterogeneous composition of the atherosclerotic tissue where several components can coexist in the same plaque. ${ }^{25,26}$ In the carotid artery plaque, coexistence of several components is frequent with changes across time. Volumetric analysis of the plaque could offer important insights because it allows us to quantify different plaque components and provides a more complete analysis. ${ }^{13,14,27,28}$ The introduction of a new CT criterion $(\leq 25 \mathrm{HU}$ of attenuation) for the detection of IPH applied to the use of volumetric quantification analysis systems could allow one to extrapolate the real impact of the IPH component. Recently published articles in $2019^{29,30}$ have demonstrated that the volumetric analysis of the carotid artery plaques obtained by CT data is a reliable technique and that small changes in plaque composition can also be detected. ${ }^{30}$

In past years, the classic division of the carotid artery plaque type according to the attenuation values was based on the seminal study by de Weert et al, ${ }^{24}$ in which 3 classes were identified: lipid $(<60 \mathrm{HU})$, mixed (between 60 and $130 \mathrm{HU})$, and calcified ( $>130$ $\mathrm{HU})$. With the demonstration that attenuation values of $<25 \mathrm{HU}$ are due to IPH, ${ }^{10}$ we tried to test the effect of the volumes for this component; therefore, the lipid class was divided into IPH $(<25$ $\mathrm{HU}$ ) and lipid-IPH (from 26 to $59 \mathrm{HU}$ ). By comparing symptomatic with asymptomatic subjects, we found a statistically significant difference in volume for the lipid $(P=.002)$, and in particular for the IPH volume $(P=.001)$. These findings confirm that IPH volume is higher in plaques causing cerebrovascular events. ${ }^{2,3,5,6,31,32}$ Of interest, there was no difference in lipid-IPH volume tissue, whereas the total lipid volume showed a statistically significant difference. This finding can be explained because in the old classification the lipid volume class included all the voxels $<60 \mathrm{HU}$ (and therefore also the IPH component); these results suggest that tissues with an attenuation between 26 to $59 \mathrm{HU}$, namely fatty components, are not associated with the presence of cerebrovascular events.

Further information can be gathered from the difference in the relative percentages of various tissue components. It is not only the volume threshold that can trigger plaque rupture but also the relative percentage, suggesting that the biomechanical structure of plaque is fundamental. In particular, in subjects with cerebrovascular symptoms, there is an increased percentage of IPH components and lipid (also including the IPH class). Conversely, in subjects without cerebrovascular symptoms, an increased percentage of calcium and lipid-IPH was found. The protective effect of the calcium was already demonstrated by 

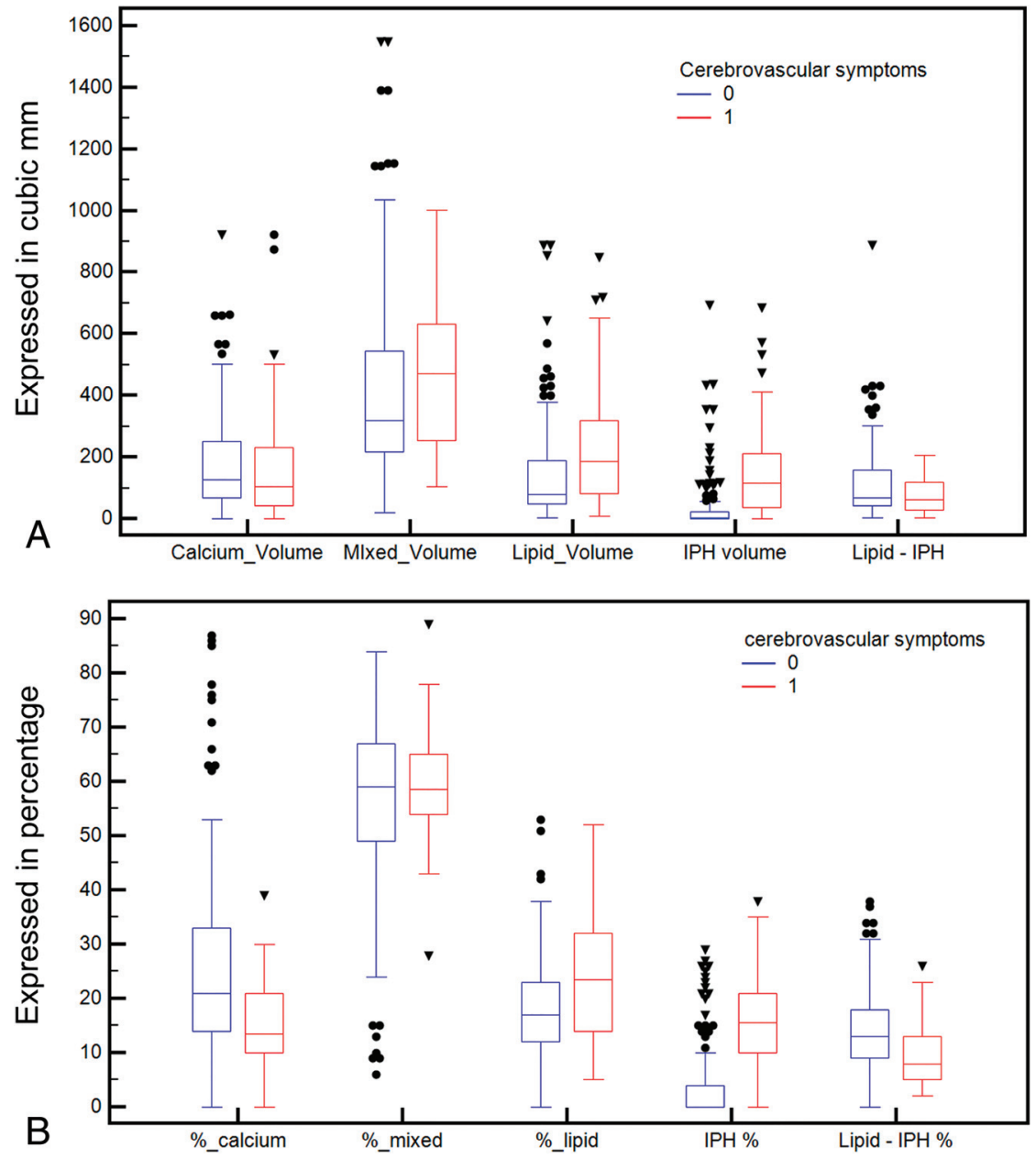

FIG 2. Boxplot of the volume components of the carotid artery plaque according to the presence or absence of cerebral symptoms $(A)$ and boxplot of the percentages of the components according to the presence or absence of cerebrovascular symptoms $(B)$.
Nandalur et $\mathrm{al}^{33}$ whereas the finding that the lipid-IPH percentage is lower in symptomatic subjects could support the histopathologic observation that lipid tissue within plaques is not active and not related to the risk of rupture. ${ }^{34}$ The ROC curve analysis confirms these results by showing the highest area under the curve with the IPH volume (AUC of $0.793, P=.001$ ) and percentage of IPH (AUC of $0.812, P=.001$ ). To assess the effect of some volumetric thresholds, we created 6 different models by considering the following thresholds: 10, 50, 100, 150, 200, and 250 $\mathrm{mm}^{3}$, and the best association was found by considering a threshold of 50 $\mathrm{mm}^{3}\left(P=.001, \chi^{2}=43.913\right.$, contingency coefficient $=0.424$ ).

Our study has some limitations. It is a retrospective analysis, and we did not explore the association between the presence of IPH (and its volume or percentage) and the risk of new/recurrent cerebrovascular events. Instead, IPH was assessed in patients who already had cerebrovascular events, and this may have introduced a bias because some plaques may have theoretically changed in structure and composition in the interval between symptom onset and the time of CTA detection. However, we think that the limited time between the symptomatic event and the CTA reduces this potential effect. Our
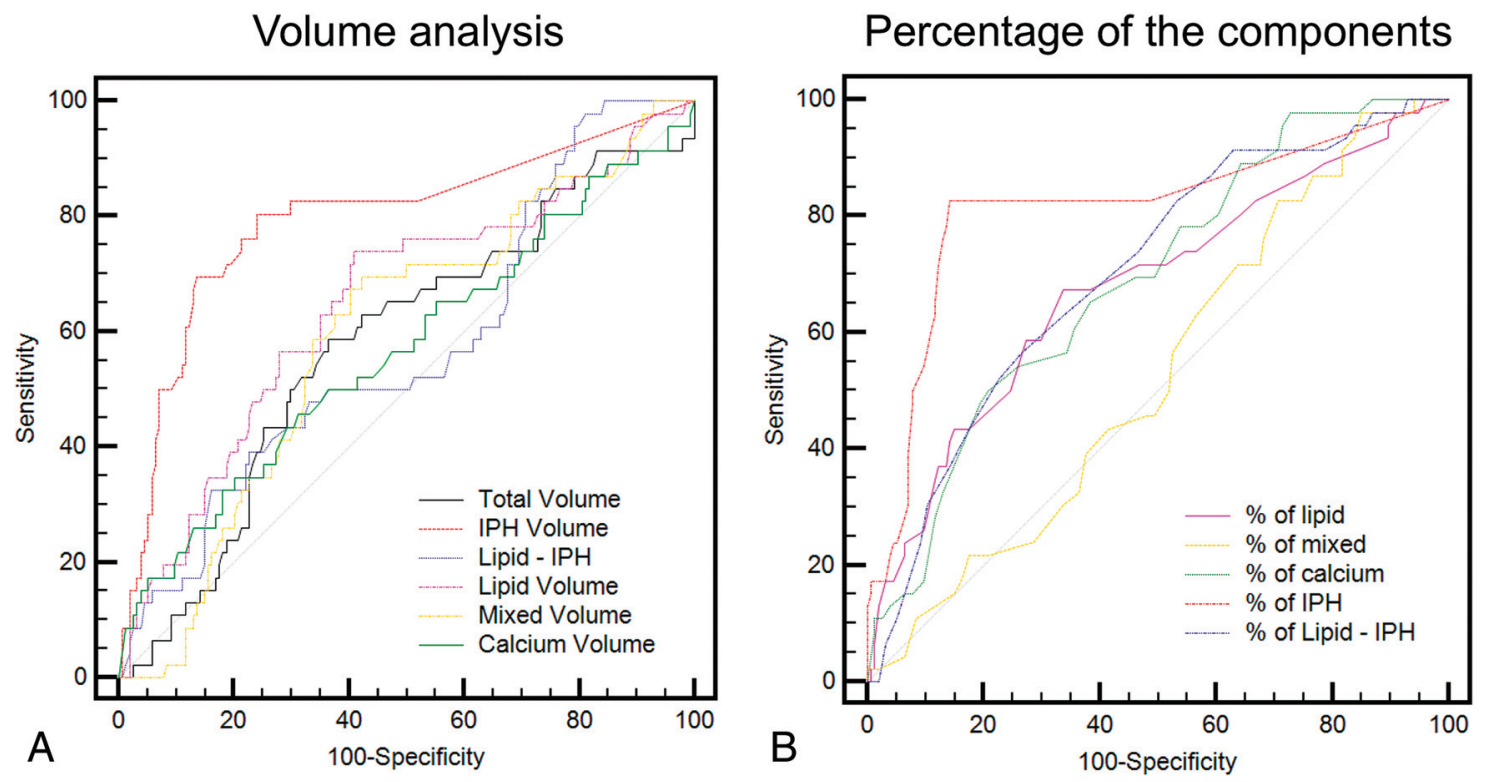

FIG 3. ROC curve analysis of the volume components of the carotid artery plaque according to the presence or absence of cerebral symptoms $(A)$ and ROC curve analysis of the percentages of the components according to the presence or absence of cerebral symptoms (B). 
Table 2: ROC curve analysis between symptoms and volume/ percentage of plaque tissues

\begin{tabular}{llllc}
\hline & AUC & \multicolumn{1}{c}{ SE } & \multicolumn{1}{c}{$95 \%$ CI } & $P$ Value \\
\hline Plaque volume & 0.579 & 0.049 & $0.507-0.648$ & .108 \\
IPH volume & 0.793 & 0.0421 & $0.730-0.847$ & .001 \\
Lipid minus IPH & 0.574 & 0.0486 & $0.502-0.643$ & .129 \\
Lipid volume & 0.648 & 0.0486 & $0.577-0.714$ & .002 \\
Mixed volume & 0.594 & 0.0465 & $0.523-0.663$ & .043 \\
Calcium volume & 0.568 & 0.0517 & $0.497-0.638$ & .186 \\
\% of lipid & 0.679 & 0.0476 & $0.609-0.743$ & .001 \\
\% of mixed & 0.532 & 0.0459 & $0.460-0.602$ & .489 \\
\% of calcium & 0.591 & 0.0426 & $0.522-0.654$ & .135 \\
\% of IPH & 0.812 & 0.0413 & $0.751-0.863$ & .001 \\
\% of lipid minus IPH & 0.702 & 0.0428 & $0.633-0.764$ & .001 \\
IPH/lipid radio & 0.811 & 0.0424 & $0.751-0.863$ & .001 \\
\hline
\end{tabular}

Note:-SE indicates standard error.

Table 3: $\chi^{2}$ test between symptoms and different volume thresholds of IPH

\begin{tabular}{lccc}
\hline & $\chi^{2}$ & Contingency Coefficient & $P$ Value \\
\hline $\mathrm{IPH}, 10 \mathrm{~mm}^{3}$ & 12.527 & 0.243 & .001 \\
$\mathrm{IPH}, 50 \mathrm{~mm}^{3}$ & 43.913 & 0.424 & .001 \\
$\mathrm{IPH}, 100 \mathrm{~mm}^{3}$ & 37.478 & 0.397 & .001 \\
$\mathrm{IPH}, 150 \mathrm{~mm}^{3}$ & 34.763 & 0.385 & .001 \\
$\mathrm{IPH}, 200 \mathrm{~mm}^{3}$ & 14.935 & 0.264 & .001 \\
$\mathrm{IPH}, 250 \mathrm{~mm}^{3}$ & 7.944 & 0.195 & .048 \\
\hline
\end{tabular}

findings are based on a relatively small cohort, and these data will need to be validated in a larger and preferentially prospective cohort. Nevertheless, these data provide a valuable framework on which further confirmatory cohorts can be based.

\section{CONCLUSIONS}

The results of this study confirm that the value of $<25 \mathrm{HU}$ has a statistically significant association with the presence of cerebrovascular events and that the ratio between IPH and lipid volume represents a strong parameter for the association of cerebrovascular events.

Disclosures: Jasjit S. Suri-UNRELATED: Other: member of AtheroPoint LLC (owner). James Kevin DeMarco-UNRELATED: Grants/Grants Pending: Department of Defense*; Payment for Lectures Including Service on Speakers Bureaus: Baptist Neurological Institute, Jacksonville, Florida; Payment for Development of Educational Presentations: International Society for Magnetic Resonance in Medicine.* Waleed Brinjikji-UNRELATED: Consultancy: Superior Medical Editing ( $<\$ 5000)$; Grants/Grants Pending: National Institutes of Health, Comments: Johnson and Johnson*; Patents (Planned, Pending or Issued): Marblehead Medical, Comments: patents pending for stroke intervention devices*; Stock/ Stock Options: Marblehead Medical, Comments: cofounder of the company. ${ }^{*}$ Money paid to the Institution

\section{REFERENCES}

1. Saba L, Yuan C, Hatsukami TS, et al. Carotid artery wall imaging: perspective and guidelines from the ASNR Vessel Wall Imaging Study Group and Expert Consensus Recommendations of the American Society of Neuroradiology. AJNR Am J Neuroradiol 2018;39:E9-31 CrossRef Medline

2. Lu M, Peng P, Cui Y, et al. Association of progression of carotid artery wall volume and recurrent transient ischemic attack or stroke: a magnetic resonance imaging study. Stroke 2018;49:614-20 CrossRef Medline

3. Saba L, Saam T, Jäger HR, et al. Imaging biomarkers of vulnerable carotid plaques for stroke risk prediction and their potential clinical implications. Lancet Neurol 2019;18:559-72 CrossRef Medline

4. Hellings WE, Peeters W, Moll FL, et al. Composition of carotid atherosclerotic plaque is associated with cardiovascular outcome: a prognostic study. Circulation 2010;121:1941-50 CrossRef Medline

5. Altaf N, MacSweeney ST, Gladman J, et al. Carotid intraplaque hemorrhage predicts recurrent symptoms in patients with high-grade carotid stenosis. Stroke 2007;38:1633 CrossRef

6. Turc G, Oppenheim C, Naggara O, HIRISC study investigators, et al. Relationships between recent intraplaque hemorrhage and stroke risk factors in patients with carotid stenosis. Arterioscler Thromb Vasc Biol 2012;32:492-99 CrossRef Medline

7. Parmar JP, Rogers WJ, Mugler JP, 3rd, et al. Magnetic resonance imaging of carotid atherosclerotic plaque in clinically suspected acute transient ischemic attack and acute ischemic stroke. Circulation 2010;122:2031-38 CrossRef Medline

8. Demarco JK, Ota H, Underhill HR, et al. MR carotid plaque imaging and contrast-enhanced MR angiography identifies lesions associated with recent ipsilateral thromboembolic symptoms: an in vivo study at 3T. AJNR Am J Neuroradiol 2010;31:1395-402 CrossRef Medline

9. Horie N, Morikawa M, Ishizaka S, et al. Assessment of carotid plaque stability based on the dynamic enhancement pattern in plaque components with multidetector CT angiography. Stroke 2012;43:393-98 CrossRef Medline

10. Saba L, Francone M, Bassareo PP, et al. CT attenuation analysis of carotid intraplaque hemorrhage. AJNR Am J Neuroradiol 2018;39:131-37 CrossRef Medline

11. Cheng J, Chen Y, Yu Y, et al. Carotid plaque segmentation from three-dimensional ultrasound images by direct three-dimensional sparse field level-set optimization. Comput Biol Med 2018;94:27-40 CrossRef Medline

12. Ball S, Rogers S, Kanesalingam $K$, et al. Carotid plaque volume in patients undergoing carotid endarterectomy. $\mathrm{Br} \mathrm{J}$ Surg 2018;105:262-69 CrossRef Medline

13. Spence JD. Approaching automated 3-dimensional measurement of atherosclerotic plaque volume. J Am Coll Cardiol 2017;70:314-17 CrossRef Medline

14. Saba L, Raz E, Anzidei M, et al. Differences in plaque morphology and correlation of stenosis at the carotid artery bifurcation and the carotid siphon. AJR Am J Roentgenol 2013;201:1108-14 CrossRef Medline

15. Touboul PJ, Hennerici MG, Meairs S, et al. Mannheim carotid intima-media thickness and plaque consensus (2004-2006-2011): an update on behalf of the advisory board of the $3 \mathrm{rd}$, 4th and 5 th watching the risk symposia, at the 13th, 15th and 20th European Stroke Conferences, Mannheim, Germany, 2004, Brussels, Belgium, 2006, and Hamburg, Germany, 2011. Cerebrovasc Dis 2004;34:290-96 Medline

16. Saba L, Sanfilippo R, Montisci R, et al. Agreement between multidetector-row CT angiography and ultrasound echo-color Doppler in the evaluation of carotid artery stenosis. Cerebrovasc Dis 2008;26:525-32 CrossRef Medline

17. Saba L, Sanfilippo R, Pascalis L, et al. Carotid artery wall thickness and ischemic symptoms: evaluation using multi-detector-row CT angiography. Eur Radiology 2008;18:1962-71 CrossRef Medline

18. Alexandrov AV, Bladin CF, Maggisano R, et al. Measuring carotid stenosis: time for a reappraisal. Stroke 1993;24:1292-96 CrossRef Medline

19. de Paiva Bezerra R, de Miranda Alves MA, Conforto AB, et al. Etiological classification of stroke in patients with Chagas Disease using TOAST, Causative Classification System TOAST, and ASCOD phenotyping. J Stroke Cerebrovasc Dis 2017;26:2864-69 CrossRef Medline 
20. Xin XY, Cheng L, Yang Z, et al. Comparison study of ASCO and TOAST classification system in Chinese minor stroke patients. Cerebrovasc Dis 2019;47:95-100 CrossRef Medline

21. Saba L, Mallarin G. Window settings for the study of calcified carotid plaques with multidetector CT angiography. AJNR Am J Neuroradiol 2009;30:1445-50 CrossRef Medline

22. Rozie S, de Weert TT, de Monyé C, et al. Atherosclerotic plaque volume and composition in symptomatic carotid arteries assessed with multidetector CT angiography; relationship with severity of stenosis and cardiovascular risk factors. Eur Radiology 2009;19:2294-301 CrossRef Medline

23. Sheahan M, Ma X, Paik D, et al. Atherosclerotic plaque tissue: noninvasive quantitative assessment of characteristics with softwareaided measurements from conventional CT angiography. Radiology 2018;286:622-31 CrossRef Medline

24. de Weert TT, de Monyé C, Meijering E, et al. Assessment of atherosclerotic carotid plaque volume with multidetector computed tomography angiography. Int J Cardiovasc Imaging 2008;24:751-59 CrossRef Medline

25. Baroncini LA, Filho AP, Ramos SG, et al. Histological composition and progression of carotid plaque. Thromb J 2007;5:4 CrossRef Medline

26. Carr S, Farb A, Pearce WH, et al. Atherosclerotic plaque rupture in symptomatic carotid artery stenosis. J Vasc Surg 1996;23:755-65 CrossRef Medline

27. Miralles M, Arrébola M, Bruguer S, et al. Volumetric assessment of the carotid bifurcation: an alternative concept to stenosis grading. Ann Vasc Surg 2015;29:411-18 CrossRef Medline
28. Saba L, Raz E, di Martino M, et al. Is there an association between asymmetry of carotid artery wall thickness (ACAWT) and cerebrovascular symptoms? Int J Neurosci 2015;125:456-63 CrossRef Medline

29. Zhu G, Li Y, Ding V, et al. Semiautomated characterization of carotid artery plaque features from computed tomography angiography to predict atherosclerotic cardiovascular disease risk score. $J$ Comput Assist Tomogr 2019 May 6 [Epub ahead of print] CrossRef Medline

30. Chrencik MT, Khan AA, Luther L, et al. Quantitative assessment of carotid plaque morphology (geometry and tissue composition) using computed tomography angiography. J Vasc Surg 2019 Mar 5. [Epub ahead of print] CrossRef Medline

31. Ajduk M, Pavić L, Bulimbasić S, et al. Multidetector-row computed tomography in evaluation of atherosclerotic carotid plaques complicated with intraplaque hemorrhage. Ann Vasc Surg 2009;23:18693 CrossRef Medline

32. Liu Y, Wang M, Zhang B, et al. Size of carotid artery intraplaque hemorrhage and acute ischemic stroke: a cardiovascular magnetic resonance Chinese atherosclerosis risk evaluation study. J Cardiovasc Magn Reson 2019;21:36

33. Nandalur KR, Baskurt E, Hagspiel KD, et al. Calcified carotid atherosclerotic plaque is associated less with ischemic symptoms than is noncalcified plaque on MDCT. AJR Am J Roentgenol 2005; 184:295-28 CrossRef Medline

34. Bentzon JF, Otsuka F, Virmani R, et al. Mechanisms of plaque formation and rupture. Circ Res 2014;114:1852-66 CrossRef Medline 